\title{
Understanding the lives of adolescents and young adults (UDAYA): Uttar Pradesh
}

Population Council

Follow this and additional works at: https://knowledgecommons.popcouncil.org/departments_sbsr-pgy

Part of the Demography, Population, and Ecology Commons, Family, Life Course, and Society Commons, International Public Health Commons, and the Maternal and Child Health Commons How does access to this work benefit you? Let us know!

\section{Recommended Citation}

Population Council. 2017. "Understanding the lives of adolescents and young adults (UDAYA): Uttar Pradesh," fact sheet. New Delhi: Population Council. 


\section{Understanding the lives of adolescents and young adults (UDAYA)}

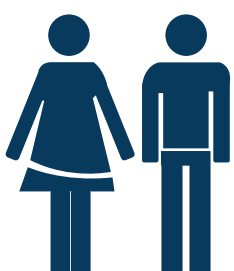

UDAYA

presents

a comprehensive picture of adolescents' situation and needs in Uttar Pradesh

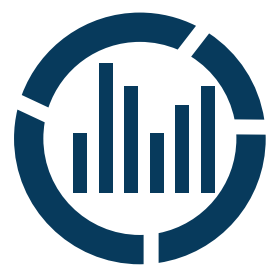

UDAYA

has a sample of 10,161 respondents: the first

ever state

representative survey of younger (10-14 years) and older (15-19 years) adolescents in Uttar Pradesh

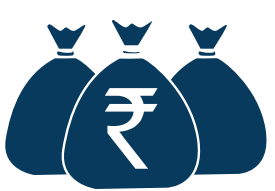

UDAYA

showcases adolescents' perspectives on government sponsored programmes for them in Uttar Pradesh

\section{CONTEXT}

Understanding the lives of adolescents and young adults (UDAYA), a programme of research conducted by the Population Council, seeks to:

- explore the situation and needs of younger (10-14 years) and older (15-19 years) adolescents;

- describe changes in their situation and needs over time; and

- assess factors that determine the quality of their transitions from adolescence to young adulthood.

UDAYA, implemented from 2015 to 2020 , uses community-based repeated cross-sectional surveys, panel surveys and qualitative methods. With its geographical focus on Bihar and Uttar Pradesh, UDAYA illustrates the lives of every fourth adolescent in India and every 16th adolescent globally.

UDAYA profiles the multiple facets of adolescents' situation:

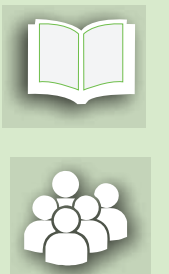

Education, employability and economic inclusion

Agency, community and citizenship

Entry into marriage and motherhood

Health and nutrition

Violence in private and public spaces

e $=$ Media and technology

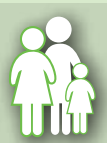

Parental engagement

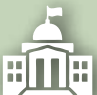

This factsheet presents findings from the first round of surveys, conducted during September 2015 to January 2016, in Uttar Pradesh, India. The study interviewed adolescents in rural and urban areas of 59 out of 75 districts in the state.

1,072 Unmarried boys (10-14 years)

2,064 Unmarried boys (15-19 years)

889 Unmarried girls (10-14 years)

4,338 Unmarried girls (15-19 years)

1,798 Married girls (15-19 years) 


\section{Education, employability and economic inclusion}

\section{Currently enrolled in school/college (\%)}

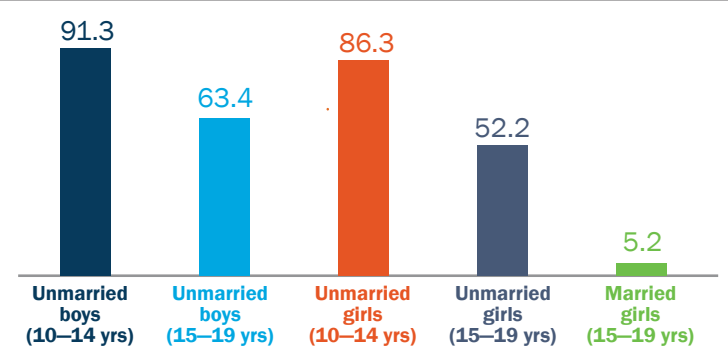

\section{Currently enrolled in a government school* (\%)}

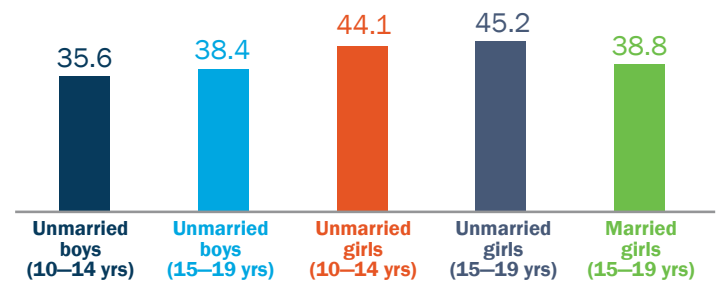

*Of those currently enrolled in school

\section{Building job skills through vocational training (\%)}

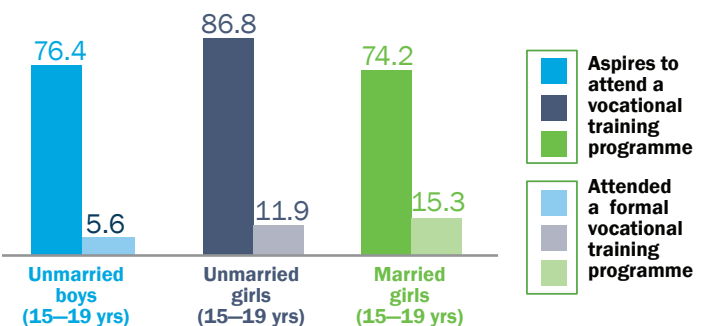

\section{Engaged in paid work* $(\%)$}
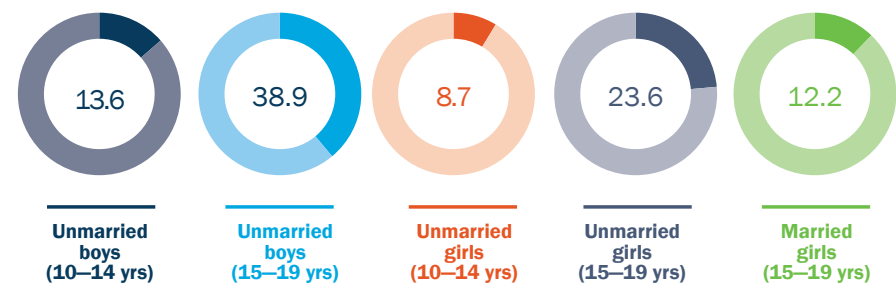

*In the last 12 months

\section{Enrolled in an age-appropriate grade* $(\%)$}

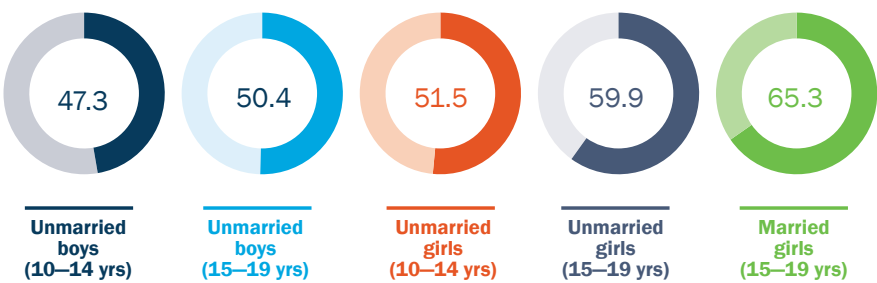

* Of those currently enrolled in school/college

Literacy and numeracy* (\%)

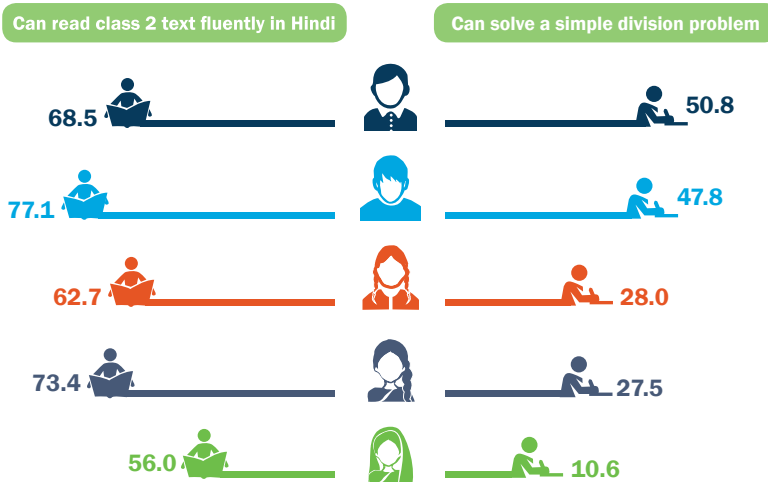

*Of those who had completed class 5

\section{Banking practices (\%)}

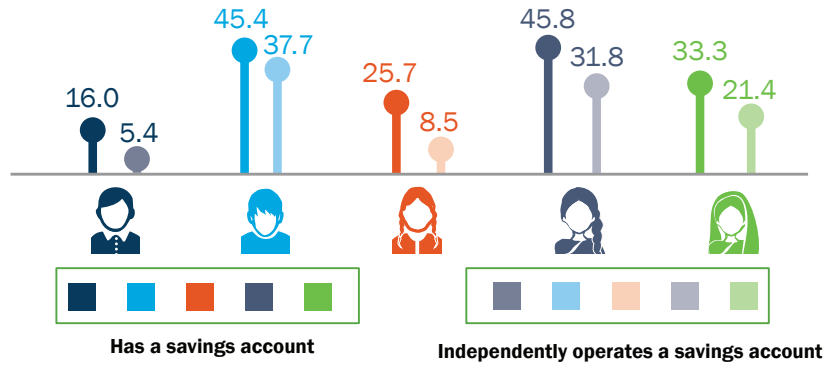

\section{Seeking jobs (\%)}
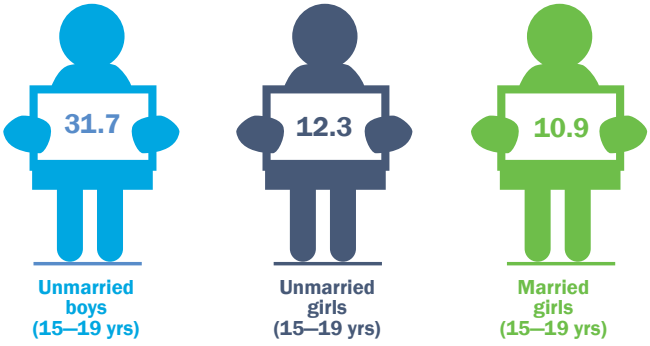


\section{Agency, community and citizenship}

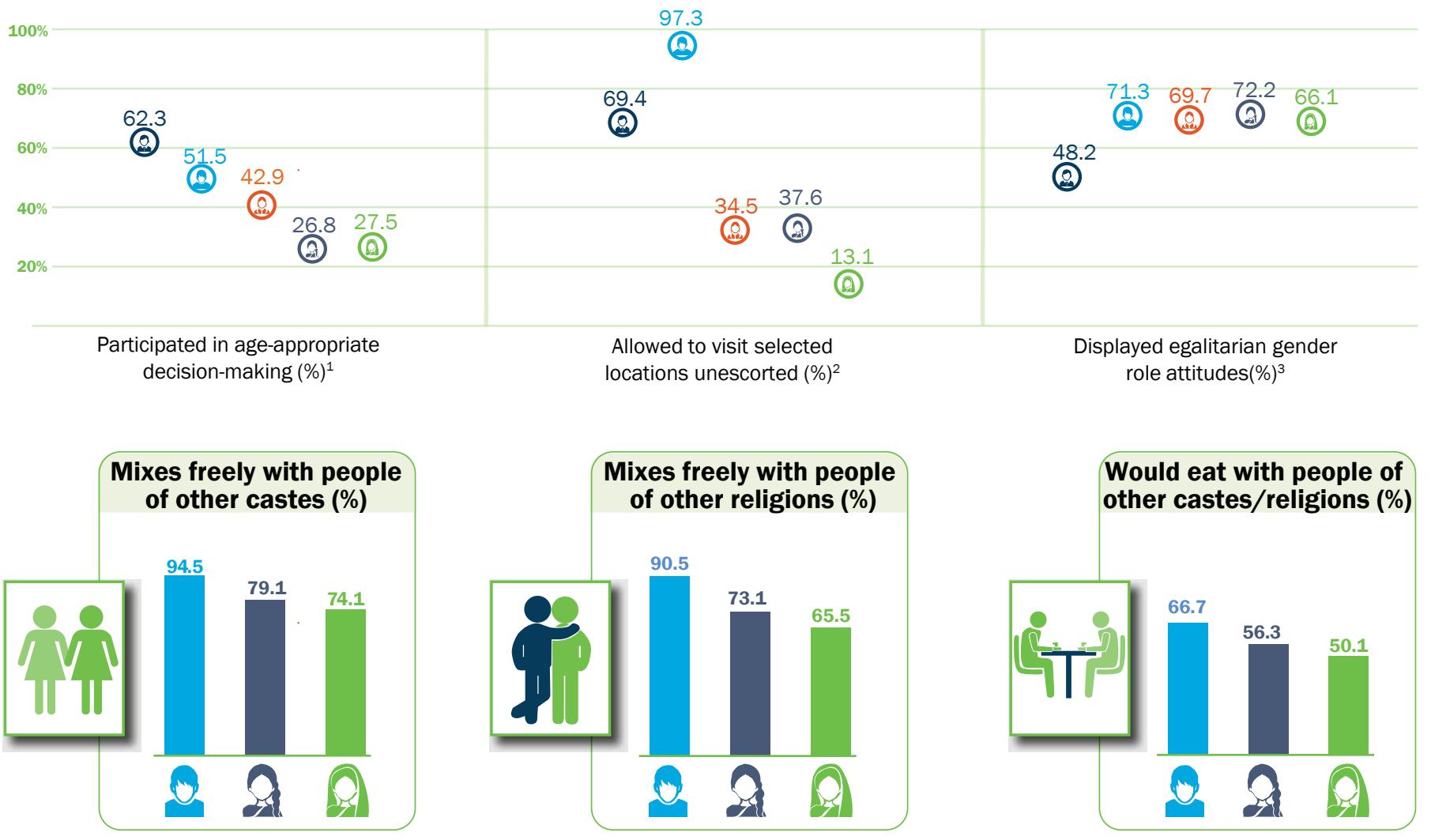

Participation in civil society and political life (\%)

Voted in the last election (\%)

Unmarried Unmarried Unmarried Unmarried Married

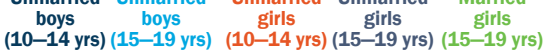

Membership in organised groups

6.8

\begin{tabular}{|r|r|r|r|}
\hline 9.5 & 2.5 & 5.0 & 4.3 \\
\hline 22.6 & - & 6.1 & 5.9 \\
\hline 93.4 & - & 82.5 & 74.9 \\
\hline
\end{tabular}

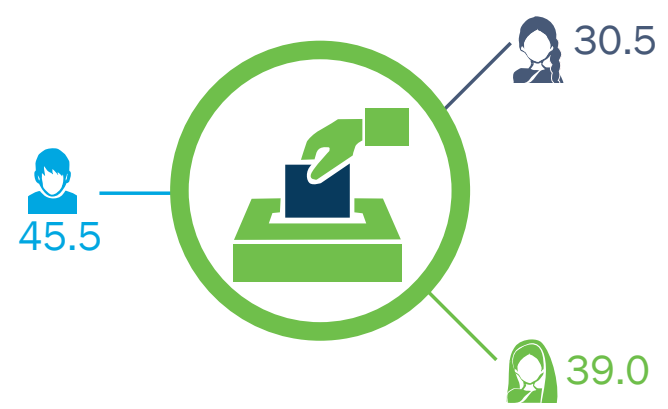

\section{Eedia and technology}
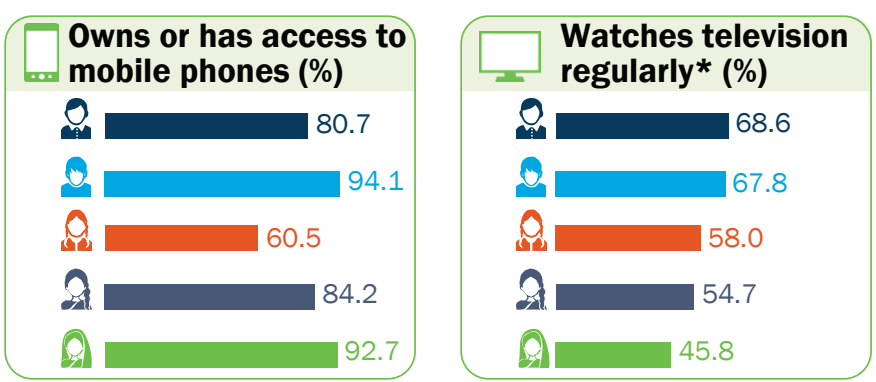

Accesses internet regularly*\# (\%)

○ 8.4

25.1

A| 1.8

A. 5.8

A. 2.9
Accesses social media regularly*\# (\%)

ㄴ.1 5.1

(3) 20.9

A 1.0

A. 4.3

Q 12.1

* Regularly includes daily or weekly exposure

\# Of those who had five or more years of schooling 


\section{Health and Nutrition}

\section{Contraceptive awareness}
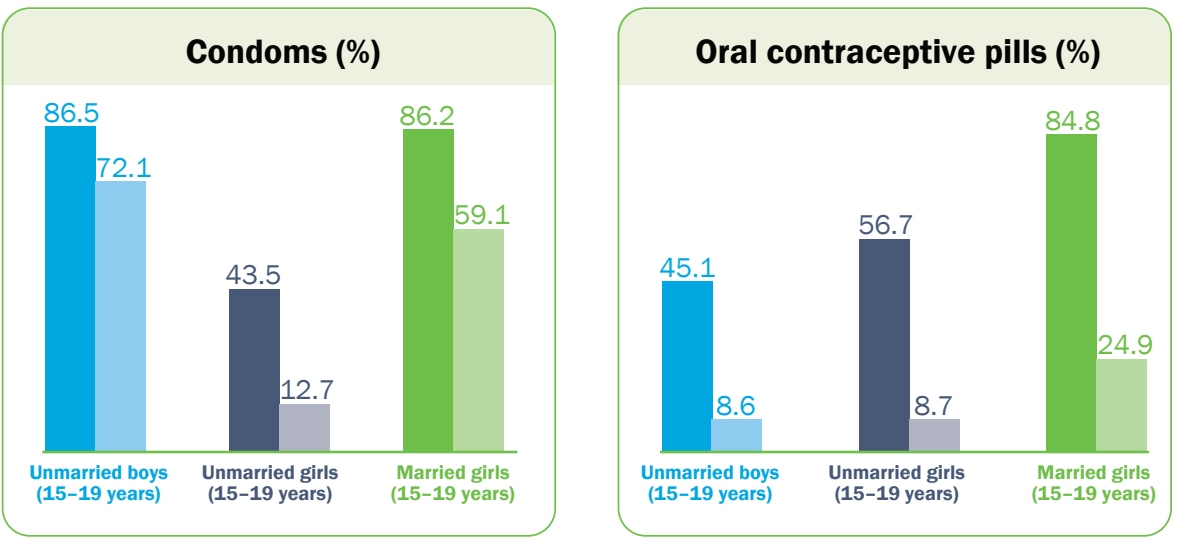

Emergency contraceptive pill (\%)

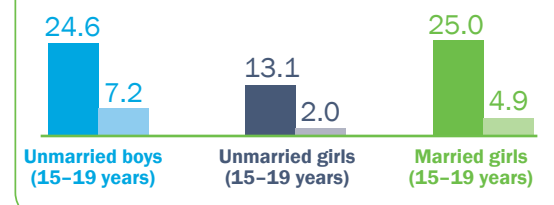

Awareness $\square \square \square$ Correct specific knowledge

\section{Practices within premarital sexual relationships (\%)}

Ever had an opposite-sex romantic partner

Ever had premarital sex

Engaged in sex before age 15 within premarital relationships*, 4

Used condom consistently within premarital relationships* ${ }^{4}$

Engaged in sex with multiple partners within premarital relationships* 4

\begin{tabular}{|c|c|c|}
\hline & & 0 \\
\hline 25.7 & 15.6 & 20.2 \\
\hline 17.4 & 6.2 & 10.0 \\
\hline 24.3 & 13.7 & 15.3 \\
\hline 14.1 & 5.3 & 8.4 \\
\hline 33.8 & 12.1 & 22.9 \\
\hline
\end{tabular}

*Of those who ever had premarital sex

\section{Contraceptive use within marriage* $(\%)$}

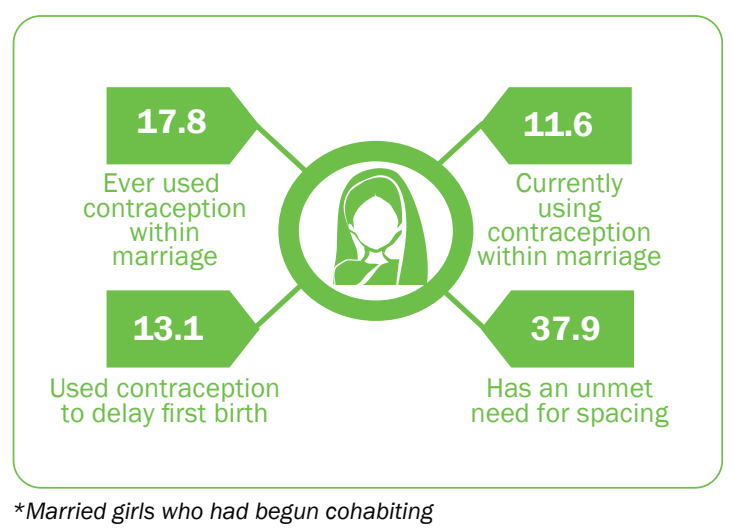

Maternal and newborn health care for first birth* (\%)

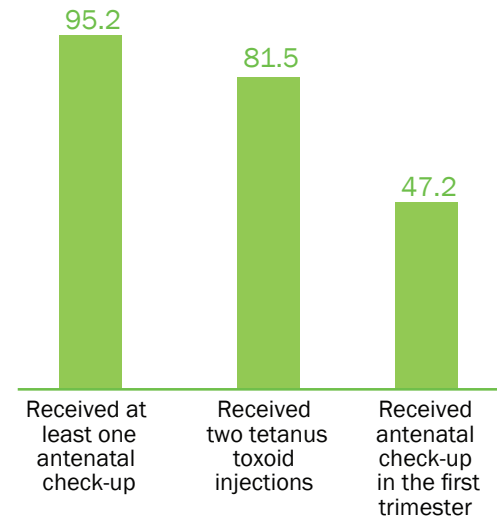

\section{$41.5 \%$}

Married girls knew that a newborn should be breastfed within an hour of birth

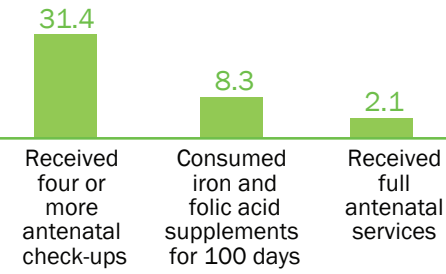

\section{$32.2 \%$}

Married girls knew that a pregnant woman should have at least four antenatal check-ups

${ }^{\star}$ Married girls who had at least one live birth

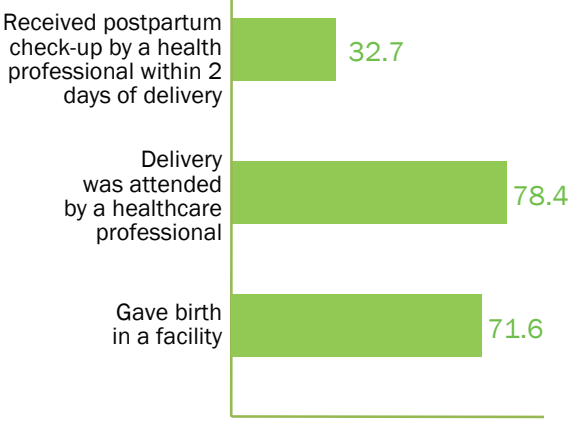

\section{$38.5 \%$}

Married girls knew that a newborn should be exclusively breastfed for six months 


\section{(ङ) Health and Nutrition}

\section{Sexual and repoductive health knowledge, attitudes and beliefs (\%)}

\begin{tabular}{|c|c|c|c|c|}
\hline $\begin{array}{c}\text { Unmarried } \\
\text { boys } \\
\text { (10-14 yrs) }\end{array}$ & $\begin{array}{c}\text { Unmarried } \\
\text { boys } \\
\text { (15-19 yrs) }\end{array}$ & $\begin{array}{c}\text { Unmarried } \\
\text { girls } \\
(10-14 \text { yrs })\end{array}$ & $\begin{array}{c}\text { Unmarried } \\
\text { girls } \\
(15-19 \mathrm{yrs})\end{array}$ & $\begin{array}{c}\text { Married } \\
\text { girls } \\
\text { (15-19 yrs }\end{array}$ \\
\hline - & 22.7 & - & 24.3 & 32.4 \\
\hline 25.8 & 56.5 & 29.8 & 64.7 & 67.6 \\
\hline - & 19.2 & - & 19.8 & 37.0 \\
\hline 10.5 & 56.6 & 8.8 & 36.5 & 30.4 \\
\hline 2.0 & 16.7 & 2.0 & 5.8 & 7.1 \\
\hline 4.8 & 9.3 & 8.6 & 17.5 & 11.1 \\
\hline
\end{tabular}

Believes that it is acceptable for a girl/woman to abort her pregnancy if she doesn't want to continue

Aware of sex determination test

Aware of sexually transmitted infections other than HIV/AIDS

Aware of HIV/AIDS

Has comprehensive knowledge of HIV/AIDS ${ }^{5}$

Received family life education* * Of adolescents $13-19$ years
Injured in a road accident* $(\%)$

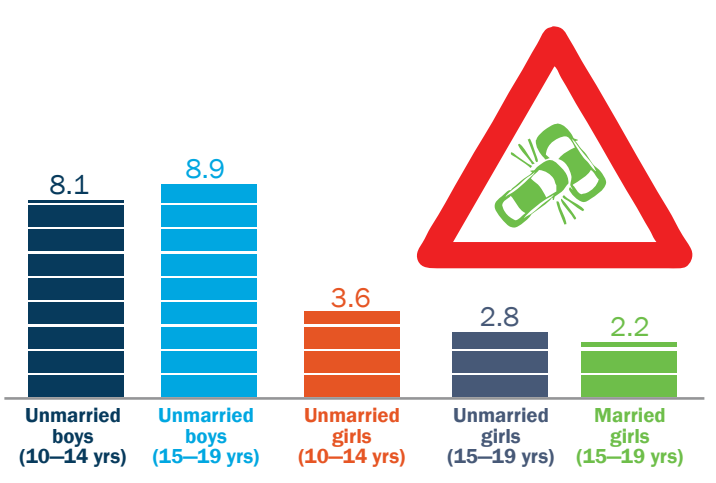

Nutritional status (\%)

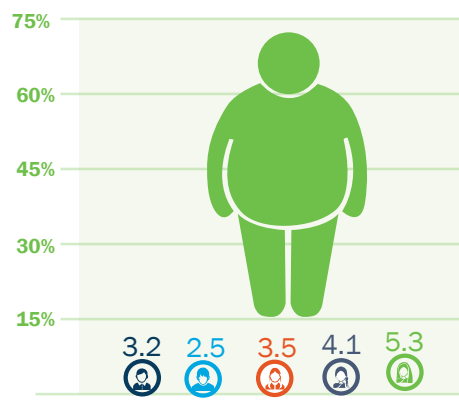

Obese or overweight ${ }^{6}$
29.6

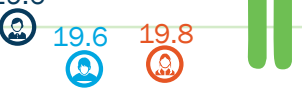

(2) (a)

Thinness $^{7}$

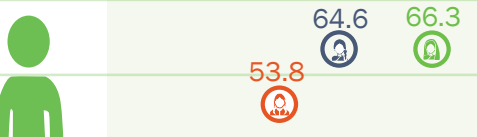

(0)

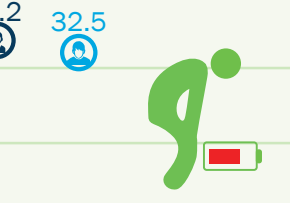

Any anaemia ${ }^{8}$

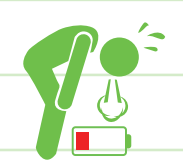

20.7 (a)
29.5
(2.) (2) (2) (2)

Moderate or severe anaemia ${ }^{9}$

\section{Mental health (\%)}

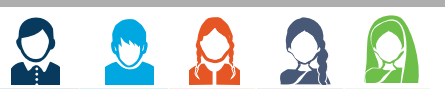

Displayed symptoms of moderate to severe depression in the last 2 weeks ${ }^{10}$ Contemplated committing suicide in the last 12 months $^{11}$

Inflicted self-harm in the last 12 months \begin{tabular}{l|l|l|l|l}
0.1 & 2.1 & 0.9 & 4.9 & 9.0
\end{tabular}

\begin{tabular}{|l|l|l|l|l|}
\hline 1.1 & 2.7 & 1.5 & 4.8 & 8.9 \\
\hline
\end{tabular}

\begin{tabular}{|l|l|l|l|l|}
\hline 5.5 & 4.3 & 7.0 & 2.7 & 3.9 \\
\hline
\end{tabular}

\section{Substance use (\%)}

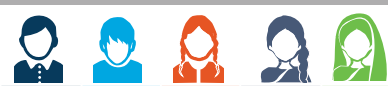

\begin{tabular}{|l|l|l|l|l|l|}
\hline Ever consumed alcohol & 0.1 & 6.6 & 0.0 & 0.1 & 0.1 \\
\hline
\end{tabular}

\begin{tabular}{|l|l|l|l|l|l|}
\hline Ever consumed drugs & 0.1 & 0.7 & 0.0 & 0.0 & 0.0
\end{tabular}

Ever consumed tobacco products

\begin{tabular}{l|l|l|l|l}
3.8 & 21.9 & 0.7 & 1.6 & 5.3 \\
\hline
\end{tabular}

\section{(Q) Entry into marriage and motherhood}
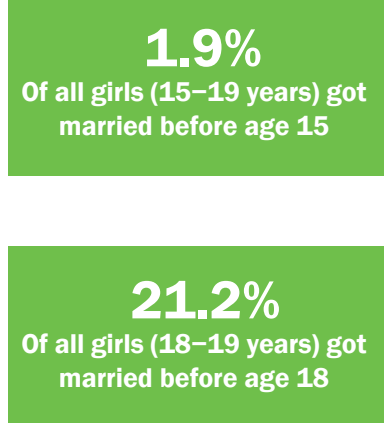

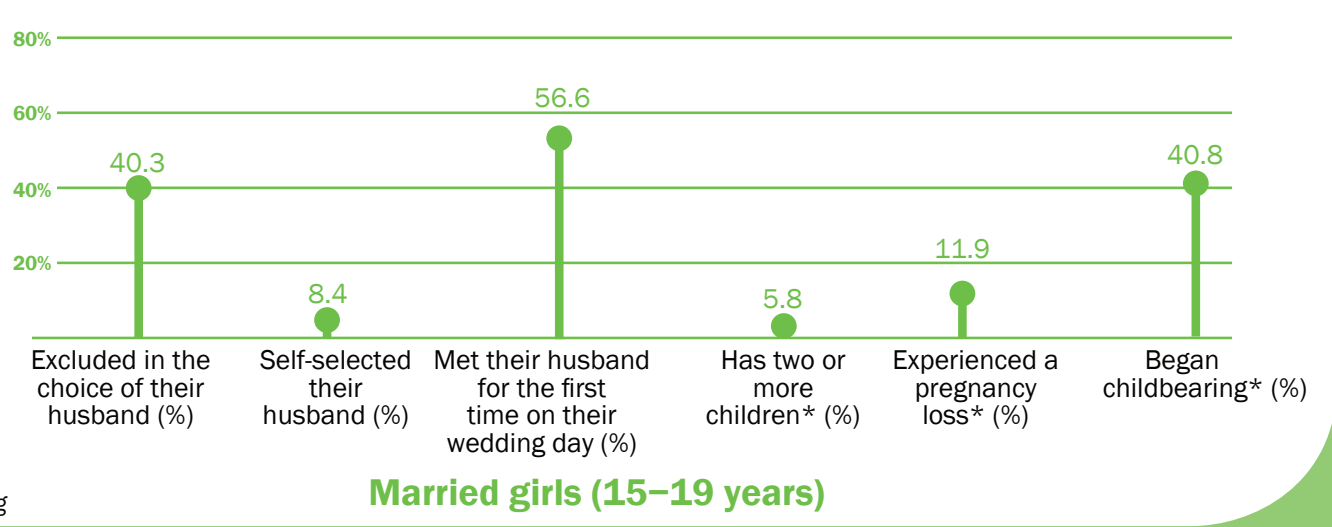




\section{CO Violence in private and public spaces}

Premarital violence* $(\%)$

Perpetrated (boys)/experienced (girls) forced sex within premarital relationships $^{12}$

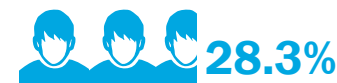

22.2929: $61.4 \%$ ๑ด@ด $51.5 \%$

*Of those who had premarital sex
Marital violence** (\%)

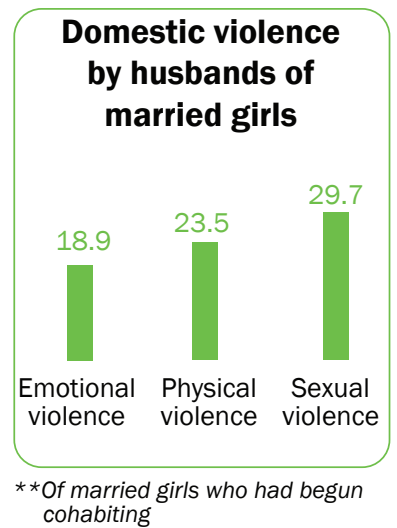

Parental violence (\%)

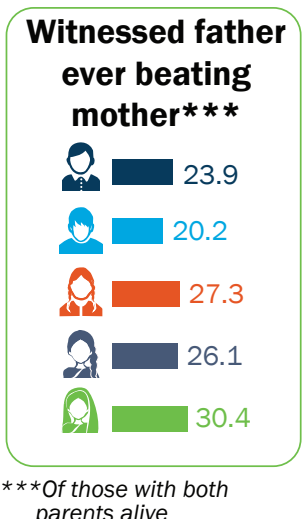

Other forms of violence (\%)

Perpetrated bullying in the last 12 months

Involved in physical fights with individuals of the same sex

Experienced mobile phone/internet based harassment

Reported familiarity with marriage-related markers of trafficking ${ }^{13}$

Believes that it is acceptable to beat up someone who insults a female family member

\begin{tabular}{|c|c|c|c|c|}
\hline $\begin{array}{c}\text { Unmarried } \\
\text { boys } \\
(\mathbf{1 0}-\mathbf{1 4} \text { yrs })\end{array}$ & $\begin{array}{c}\text { Unmarried } \\
\text { boys }\end{array}$ & $\begin{array}{c}\text { Unmarried } \\
\text { girls }\end{array}$ & $\begin{array}{c}\text { Unmarried } \\
\text { (10-14 yrs) }\end{array}$ & $\begin{array}{c}\text { Married } \\
\text { girls }\end{array}$ \\
\hline 25.4 & 17.9 & 23.8 & 10.2 & 2.1 \\
\hline 44.9 & 26.6 & 29.5 & 9.8 & 1.9 \\
\hline 0.5 & 2.8 & 0.9 & 2.4 & 3.5 \\
\hline 1.4 & 2.6 & 2.7 & 8.5 & 12.0 \\
\hline 59.1 & 65.6 & 46.0 & 41.0 & 38.7 \\
\hline
\end{tabular}

\section{Parental engagement (\%)}

Adolescents whose mother had no formal schooling

Acknowledged at least one form of favourable (boys)/discriminatory (girls) practices by their parents*

Discussed friends with their mother in the last year**

Discussed friends with their father in the last year**

Discussed reproductive processes with their mother in the last year**

Discussed reproductive processes with their father in the last year**

Considered parents as their role model $* * *$

Identified parents as their source for learning social behaviours

* Of those co-residing with a brother/sister with age gap of up to three years

** Of those with at least one parent alive

*** Of those who reported their having a role model

\begin{tabular}{|c|c|c|c|c|}
\hline $\begin{array}{c}\text { Unmarried } \\
\text { boys } \\
(10-14 \mathrm{yrs})\end{array}$ & $\begin{array}{c}\text { Unmarried } \\
\text { boys } \\
\text { (15-19 yrs) }\end{array}$ & $\begin{array}{c}\text { Unmarried } \\
\text { girls } \\
(10-14 \mathrm{yrs})\end{array}$ & $\begin{array}{c}\text { Unmarried } \\
\text { girls } \\
(15-19 \mathrm{yrs})\end{array}$ & $\begin{array}{c}\text { Married } \\
\text { girls } \\
(15-19 \mathrm{yrs})\end{array}$ \\
\hline 68.4 & 66.7 & 65.7 & 69.2 & 83.1 \\
\hline 16.4 & 18.6 & 27.9 & 25.8 & - \\
\hline 46.3 & 40.3 & 68.1 & 61.1 & - \\
\hline 31.1 & 34.6 & 23.2 & 21.8 & - \\
\hline - & 0.6 & - & 2.1 & - \\
\hline - & 1.0 & - & 0.4 & - \\
\hline 22.7 & 13.4 & 26.7 & 25.3 & 38.0 \\
\hline 83.6 & 87.1 & 86.5 & 85.9 & 83.0 \\
\hline
\end{tabular}




\section{嚼 Entitlements}

\section{Education entitlements (\%)}

Unmarried Unmarried Unmarried Unmarried Married

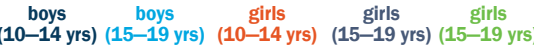

Aware of scholarship schemes* ${ }^{14}$

(98.2)

94.3

(32.2)

Received a scholarship *,14

Aware of provision of free textbooks * ${ }^{15}$

Received free textbooks * ${ }^{15}$

Aware of provision of free uniforms * ${ }^{15}$

Received free uniforms* 15

Received laptop/tablet**,16

96.2

87.2

96.5

77.5

*Those enrolled in an eligible class in a government school at

**Of those who passed out of Class 10 or 12 in the last year

* Percentage not shown because this was based on fewer than 25 unweighted cases

() Based on 25-49 unweighted cases
Received mid-day meal on the last day that $\mathrm{s} /$ he attended school* (\%)

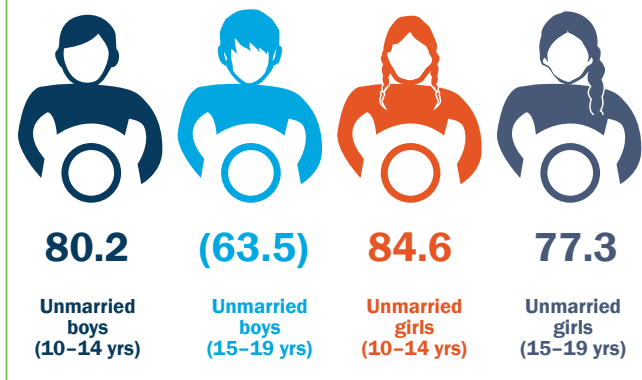

* Of those currently enrolled in eligible classes in a government school

() Based on 25-49 unweighted cases

\section{Livelihood entitlements (\%)}

\section{5}

Aware of Utta

Pradesh Skill

Development

Mission

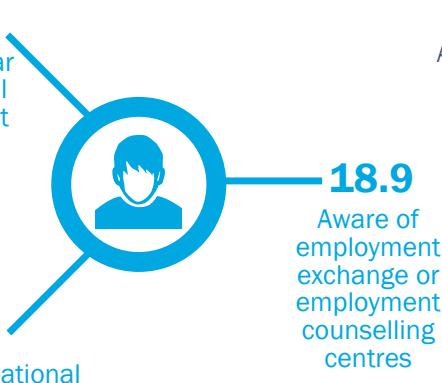

Aware of vocational

training centres that

offer training under

Uttar Pradesh Skill

Development Mission

\section{2}

Aware of Uttar
Pradesh Skill
Development

Mission
Mision

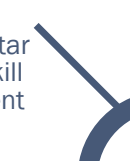

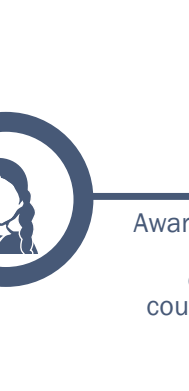

8.2

Aware of vocational

training centres that offer

training under Uttar

Pradesh Skill Development

Mission

\section{1}

Aware of Uttar Pradesh Skill Development Mission

\section{6}

are of employment

exchange or

employment

counselling centres

4.7

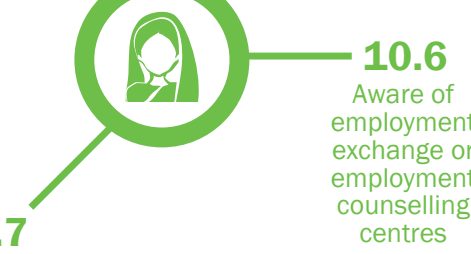

Aware of vocational

training centres that

offer training under

Uttar Pradesh Skill

Development Mission

\section{Health entitlements (\%)}

Unmarried Unmarried Unmarried Unmarried Married

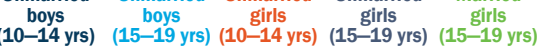

Aware of weekly iron and folic acid

supplementation (WIFS) scheme

Received iron and folic acid tablets

under WIFS in the last year

Received de-worming tablets under

WIFS in the last year

Aware of adolescent friendly health clinics

Aware of accredited social health

activists (ASHAs)

Interacted with an ASHA in the last year

Aware of anganwadi workers

Interacted with an anganwadi worker in the last year

\begin{tabular}{|r|r|r|r|r|}
\hline 25.9 & 24.6 & 32.5 & 34.8 & 36.2 \\
\hline 6.9 & 2.7 & 7.8 & 5.0 & 4.0 \\
\hline 9.4 & 5.0 & 9.1 & 5.7 & 2.0 \\
\hline 1.2 & 3.1 & 2.1 & 4.8 & 4.4 \\
\hline 54.6 & 73.6 & 59.8 & 82.9 & 86.0 \\
\hline 2.5 & 1.5 & 2.6 & 3.7 & 24.2 \\
\hline 82.2 & 91.1 & 84.4 & 92.8 & 90.2 \\
\hline 7.8 & 2.0 & 8.5 & 5.3 & 20.1 \\
\hline
\end{tabular}
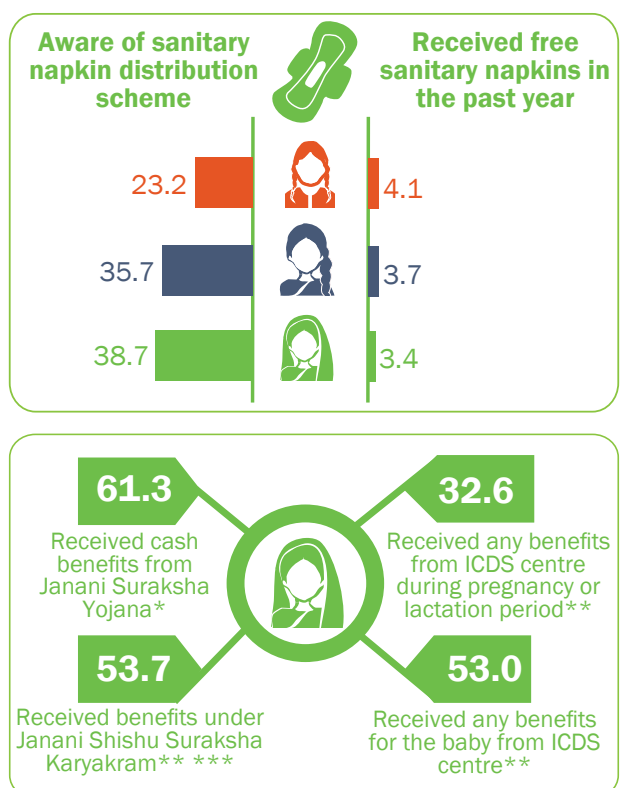

* Of those whose first birth took place in a government

** Married girls with at least one live birth

*** Of those whose first delivery took place in a public or private health facility 


\section{POPULATION COUNCIL}

Ideas. Evidence. Impact.

The Population Council confronts critical health and development issues-from stopping the spread of HIV to improving reproductive health and ensuring that young people lead full and productive lives. Through biomedical, social science, and public health research in 50 countries, we work with our partners to deliver solutions that lead to more effective policies, programs, and technologies that improve lives around the world. Established in 1952 and headquartered in New York, the Council is a nongovernmental, nonprofit organization governed by an international board of trustees.

\section{Suggested citation:}

Population Council. 2017. UDAYA - Understanding the lives of adolescents and young adults: Uttar Pradesh. Factsheet 2015-16. New Delhi: Population Council.

For additional copies, please contact:
1. The questions about decision- making were different for younger and older adolescents; younger adolescents were asked about their participation in decisions related to years of schooling they should have, their choice of friends and going to a friend's house; older adolescents were asked about their participation in decisions related to years of schooling they should have, major household purchases and whether to work or stay at home. The percentage reflects those who reported some say in all the three decisions and the analysis pertaining to this indicator has been restricted to those who were enrolled in school as the question about the level of schooling they should have was posed only to those who were ever enrolled in school. Given that younger and older adolescents were asked different questions, comparisons between these groups are not advised for this indicator.

2. Both younger and older adolescents were asked whether they were allowed to visit locations such as a shop/market or a friend/relative within their village/ward, a shop/market or a friend/relative outside their village/ward, and a programme (mela,sports event, adolescent group meetings) within their village/ward; the percentage reflects those who were allowed to visit two out of three locations unescorted.

3. Refers to respondents who expressed a gender egalitarian attitude in four out of six statements posed to them; these statements referred to: the relative importance of educating boys versus girls, comparative performance of girls versus boys in studies, and boys' sharing household chores with their sisters (for 10-14 year-olds); fathers and mothers sharing chores related to childcare, a girl having male friend, and a man's perceived right to beat his wife if she does not listen to or obey him (for 15-19 year-olds): and girls' interest in being teased by boys, girls' right to be involved in decisions related to timing of their marriage, and fathers'/husbands' perceived right to decide about spending household money (for both 10-14 year-olds and 15-19 year-olds). Given that younger and older adolescents were asked different questions, comparisons between these groups are not advised for this indicator.

4. Among those who had reported premarital sex via face-to-face interview.

5. Comprehensive awareness of HIV/AIDS for 15-19-year-old adolescents includes: (1) identifying two major ways of preventing HIV (using condoms always and limiting sex to one partner); (2) rejecting three common misconceptions about HIV transmission (that HIV can be transmitted through mosquito bites, sharing food with a person who has HIV, and hugging someone who has HIV); and (3) knowing that a healthy-looking person can be HIV-positive. Comprehensive awareness of HIV/AIDS for 10-14-year-old adolescents includes: (1) rejecting three common misconceptions about HIV transmission (that HIV can be transmitted through mosquito bites, sharing food with a person who has HIV, and hugging someone who has HIV); and (2) knowing that a healthy-looking person can be HIV-positive.

6. The criterion for being obese or overweight was defined as BMI-for-age Z score $>+1 \mathrm{SD}$ using 2007 WHO reference data.

7. Thinness was defined as BMI-for-age $Z$ score <- 2SD, using 2007 WHO reference data.

8. Any anemia: $<11.5 \mathrm{~g} / \mathrm{dl}$ for $10-11$ year olds; $<12.0 \mathrm{~g} / \mathrm{dl}$ for $12-14$ year-olds and non-pregnant girls aged 15 years and above; $<11.0 \mathrm{~g} / \mathrm{dl}$ for pregnant girls aged 15 years and above; $<13.0 \mathrm{~g} / \mathrm{dl}$ for boys aged 15 years and above.

9. Moderate anaemia: 7.0-9.9 g/dl for 10-14 year old and girls aged 15-19 years, regardless of pregnancy status at the time of the interview, and $9.0-11.9 \mathrm{~g} / \mathrm{dl}$ for boys aged 15-19 years; Severe anaemia: $<7.0 \mathrm{~g} / \mathrm{dl}$ for $10-14$ year-olds and girls aged $15-19$, regardless of pregnancy status, and $<9.0 \mathrm{~g} / \mathrm{dl}$ for boys aged $15-19$ years.

10. We administered Patient Health Questionnaire- 9 and the percentage shows those who scored $10-27$ on a scale that ranged from 0-27; specifically, a score of 10-14 indicates symptoms of moderate depression, 15-19 moderately severe and 20-27 severe depression.

11. Asked of respondents aged 13 and above.

12. Among those who had reported pre-marital sex via face-to-face interview or anonymous format (through sealed envelope).

13. Girls were asked whether they or any other girls of their age in their family had ever been taken elsewhere with false promises of marriage and whether their parents or guardians had ever been approached by acquaintances or strangers with offers of marriage to grooms from outside their state for themselves or any other girl of their age in their family. Boys were asked whether their sisters or any other girls of their age in their family had received such offers. We recognise that responses to these questions may include both genuine and exploitative offers of and marriage and caution that findings may overestimate the extent of potential risk of trafficking; on the other hand, it is also likely that genuine cases of trafficking may not be reported in a large survey, and hence, findings may underestimate the risk of trafficking as well. We suggest that findings are viewed in this light.

14. Number of adolescents enrolled in Class 9 or above at the time of the interview or completed Class 9 or above in the year preceding the interview in a government school.

15. Number of adolescents enrolled in Class 1-8 at the time of the interview or completed Class $1-8$ in the year preceding the interview in a government school.

16. Number of adolescents who passed out of Class 10 or 12 in the year preceding the interview; excludes 56 older boys, 140 unmarried older girls and 51 married girls who were pursuing their education through distance education programme for whom data on the receipt of tablet/laptop were not collected.

\section{Study supported by}

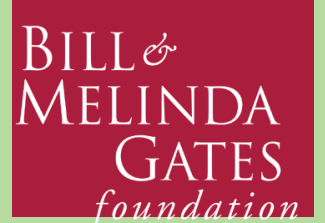

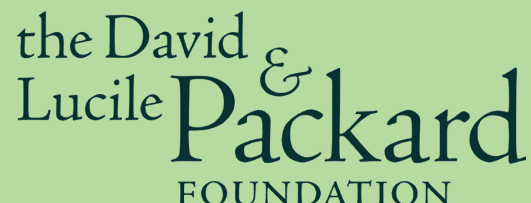

